\title{
Peritumoral immune infiltrates in primary tumours are not associated with the presence of axillary lymph node metastasis in breast cancer: A retrospective cohort study
}

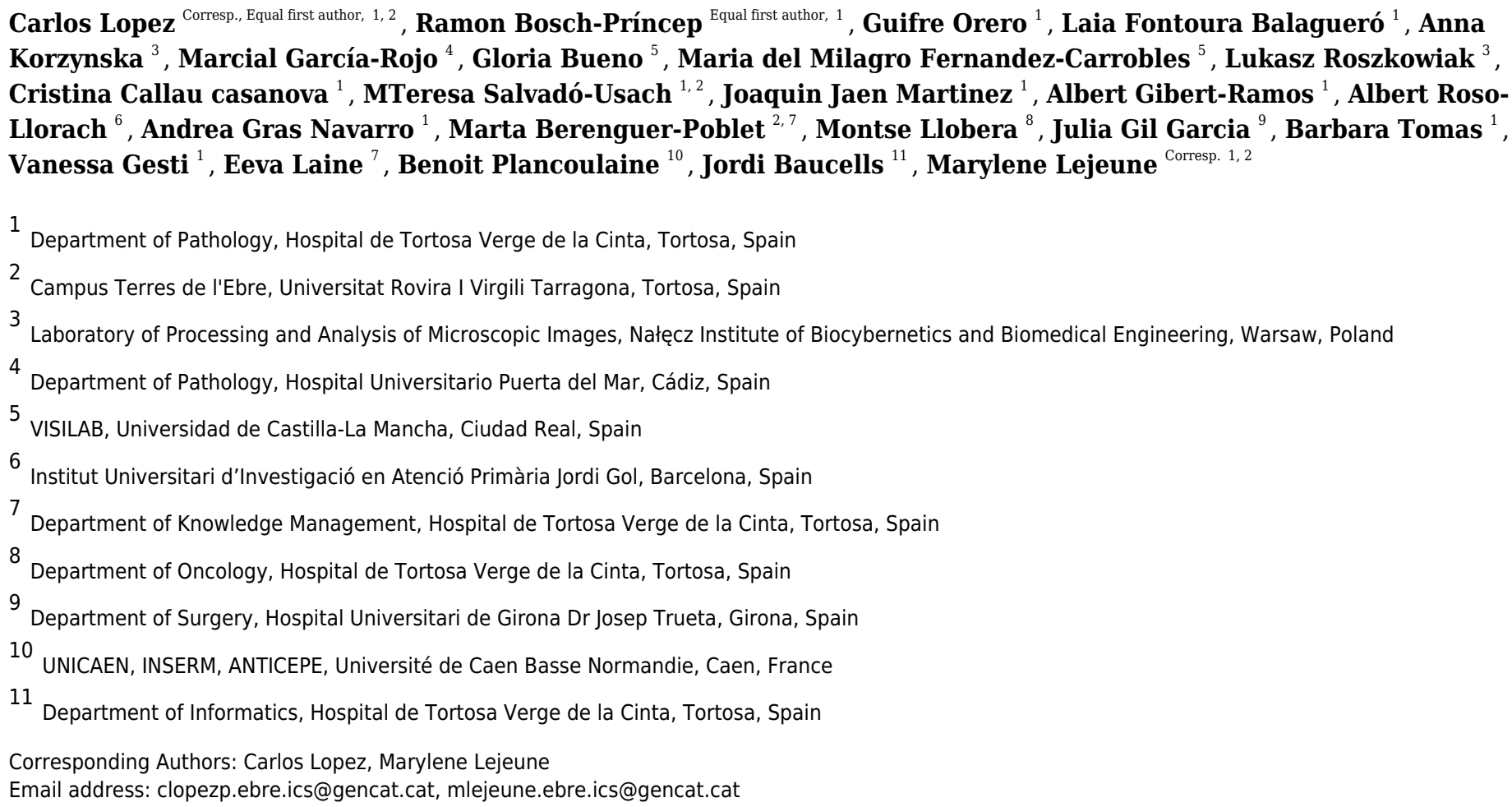

Background. The axillary lymph nodes (ALNs) in breast cancer patients are the body regions to where tumoral cells most often first disseminate. The tumour immune response is important for breast cancer patient outcome, and some studies have evaluated its involvement in ALN metastasis development. Most studies have focused on the intratumoral immune response, but very few have evaluated the peritumoral immune response. The aim of the present article is to evaluate the immune infiltrates of the peritumoral area and their association with the presence of ALN metastases. Methods. The concentration of 11 immune markers in the peritumoral areas was studied in 149 patients diagnosed with invasive breast carcinoma of no special type (half of whom had ALN metastasis at diagnosis) using tissue microarrays, immunohistochemistry and digital image analysis procedures. The differences in the concentration of the immune response of peritumoral areas between patients diagnosed with and without metastasis in their ALNs were evaluated. A multivariate logistic regression model was developed to identify the clinical-pathological variables and the peritumoral immune markers independently associated with having or not having ALN metastases at diagnosis. Results. No 
statistically significant differences were found in the concentrations of the 11 immune markers between patients diagnosed with or without ALN metastases. Patients with metastases in their ALNs had a higher histological grade, more lymphovascular and perineural invasion and larger-diameter tumours. The multivariate analysis, after validation by bootstrap simulation, revealed that only tumour diameter $(\mathrm{OR}=1.04 ; 95 \% \mathrm{Cl}$ : 1.00-1.07; $p=0.026)$, lymphovascular invasion ( $O R=25.42 ; 95 \% \mathrm{Cl}: 9.57-67.55 ; \mathrm{p}<0.001$ ) and histological grades $2(\mathrm{OR}=3.84 ; 95 \% \mathrm{Cl}$ : 1.11-13.28; $\mathrm{p}=0.033)$ and $3(\mathrm{OR}=5.18 ; 95 \%$ $\mathrm{Cl}: 1.40-19.17 ; \mathrm{p}=0.014$ ) were associated with the presence of ALN metastases at diagnosis. This study is one of the first to study the association of the peritumoral immune response with ALN metastasis. We did not find any association of peritumoral immune infiltrates with the presence of ALN metastasis. Nevertheless, this does not rule out the possibility that other peritumoral immune populations are associated with ALN metastasis. This matter needs to be examined in greater depth, broadening the types of peritumoral immune cells studied, and including new peritumoral areas, such as the germinal centres of the peritumoral tertiary lymphoid structures found in extensively infiltrated neoplastic lesions. 
1 Peritumoral immune infiltrates in primary tumours are

2 not associated with the presence of axillary lymph

3 node metastasis in breast cancer: a retrospective

4 cohort study

5

6

7

8

9

Running title: Peritumoral immune response in $\mathrm{BC}$

Carlos Lopez,,${ }^{1,{ }^{*} \dagger}$ Ramon Bosch-Príncep,${ }^{1 *}$ Guifre Orero, ${ }^{1}$ Laia Fontoura Balagueró, ${ }^{1}$ Anna Korzynska, ${ }^{3}$ Marcial García-Rojo, ${ }^{4}$ Gloria Bueno, ${ }^{5}$ Maria del Milagro Fernandez-Carrobles, ${ }^{5}$ Lukasz Roszkowiak, ${ }^{3}$ Cristina Callau Casanova, ${ }^{1}$ MTeresa Salvadó-Usach, ${ }^{1,2}$ Joaquin Jaen Martinez, ${ }^{1}$ Albert Gibert-Ramos, ${ }^{1}$ Albert Roso-Llorach, ${ }^{6}$ Andrea Gras Navarro, ${ }^{1}$ Marta Berenguer-Poblet, ${ }^{2,7}$ Montse Llobera, ${ }^{8}$ Julia Gil Garcia, ${ }^{9}$ Barbara Tomas, ${ }^{1}$ Vanessa Gesti, ${ }^{1}$ Eeva Laine, ${ }^{7}$ Benoit Plancoulaine, ${ }^{10}$ Jordi Baucells, ${ }^{11}$ Marylene Lejeune. ${ }^{1,2 \dagger}$

*Both authors contributed equally to the study.

${ }^{1}$ Department of Pathology, Hospital de Tortosa Verge de la Cinta, Tortosa, Spain.

${ }^{2}$ Campus Terres de l'Ebre, Universitat Rovira i Virgili, Tortosa, Spain.

${ }^{3}$ Laboratory of Processing and Analysis of Microscopic Images, Nalęcz Institute of Biocybernetics and Biomedical Engineering, Warsaw, Poland.

${ }^{4}$ Department of Pathology, Hospital Universitario Puerta del Mar, Cádiz, Spain.

${ }^{5}$ VISILAB, Universidad de Castilla-La Mancha, Ciudad Real, Spain.

${ }^{6}$ Institut Universitari d'Investigació en Atenció Primària Jordi Gol, Barcelona, Spain.

${ }^{7}$ Department of Knowledge Management, Hospital de Tortosa Verge de la Cinta, Tortosa, Spain.

${ }^{8}$ Department of Oncology, Hospital de Tortosa Verge de la Cinta, Tortosa, Spain.

${ }^{9}$ Department of Surgery, Hospital Universitari de Girona Dr. Josep Trueta, Girona, Spain.

${ }^{10}$ UNICAEN, INSERM, ANTICIPE, Université de Caen Basse Normandie, Caen, France.

${ }^{11}$ Department of Informatics, Hospital de Tortosa Verge de la Cinta, Tortosa, Spain.

\section{Corresponding authors:}

Carlos Lopez

C/ Esplanetes no 14, 43500-Tortosa, Tarragona, Spain.

E-mail: clopezp.ebre.ics@gencat.cat / clpclp3@gmail.com

Marylene Lejeune

C/ Esplanetes no 14, 43500-Tortosa, Tarragona, Spain. 
40 E-mail: mlejeune.ebre.ics@gencat.cat

41 Abstract

42 Background. The axillary lymph nodes (ALNs) in breast cancer patients are the body regions to

43 where tumoral cells most often first disseminate. The tumour immune response is important for

44 breast cancer patient outcome, and some studies have evaluated its involvement in ALN

45 metastasis development. Most studies have focused on the intratumoral immune response, but

46 very few have evaluated the peritumoral immune response. The aim of the present article is to

47 evaluate the immune infiltrates of the peritumoral area and their association with the presence of

48 ALN metastases. Methods. The concentration of 11 immune markers in the peritumoral areas

49 was studied in 149 patients diagnosed with invasive breast carcinoma of no special type (half of

50 whom had ALN metastasis at diagnosis) using tissue microarrays, immunohistochemistry and

51 digital image analysis procedures. The differences in the concentration of the immune response

52 of peritumoral areas between patients diagnosed with and without metastasis in their ALNs were

53 evaluated. A multivariate logistic regression model was developed to identify the clinical-

54 pathological variables and the peritumoral immune markers independently associated with

55 having or not having ALN metastases at diagnosis. Results. No statistically significant

56 differences were found in the concentrations of the 11 immune markers between patients

57 diagnosed with or without ALN metastases. Patients with metastases in their ALNs had a higher

58 histological grade, more lymphovascular and perineural invasion and larger-diameter tumours.

59 The multivariate analysis, after validation by bootstrap simulation, revealed that only tumour

60 diameter $(\mathrm{OR}=1.04 ; 95 \% \mathrm{CI}: 1.00-1.07 ; \mathrm{p}=0.026)$, lymphovascular invasion $(\mathrm{OR}=25.42 ; 95 \%$

61 CI: 9.57-67.55; $\mathrm{p}<0.001)$ and histological grades $2(\mathrm{OR}=3.84 ; 95 \% \mathrm{CI}: 1.11-13.28 ; \mathrm{p}=0.033)$ and

$623(\mathrm{OR}=5.18 ; 95 \% \mathrm{CI}: 1.40-19.17 ; \mathrm{p}=0.014)$ were associated with the presence of ALN

63 metastases at diagnosis. This study is one of the first to study the association of the peritumoral

64 immune response with ALN metastasis. We did not find any association of peritumoral immune

65 infiltrates with the presence of ALN metastasis. Nevertheless, this does not rule out the

66 possibility that other peritumoral immune populations are associated with ALN metastasis. This

67 matter needs to be examined in greater depth, broadening the types of peritumoral immune cells

68 studied, and including new peritumoral areas, such as the germinal centres of the peritumoral

69 tertiary lymphoid structures found in extensively infiltrated neoplastic lesions. 


\section{Introduction}

71 Breast cancer (BC) patients with axillary lymph node (ALN) metastasis have a higher risk of

72 distant metastases and death within 10 years of diagnosis. The primary cause of death in cancer

73 patients is distant metastasis, most of which are incurable (Siegel et al. 2017).

74

75

76

77

78

79

80

81

82

83

84

85

86

87

88

89

90

91

92

93

94

95

96

97

98

99

100

101

102

103

104

105

106

107

108

Immune cells are an important class of cells that are involved in tumoral progression (Gardner \& Ruffell 2016; Hanahan \& Coussens 2012; Weber \& Kuo 2012). The immune system protects against tumours, but cancer cells induce changes in the immune response, enabling them to evade immune destruction (Corthay 2014). In most cases, the immune reaction against the tumour alone is ineffective at eliminating cancer cells due to the immunoediting and/or immunosubversion produced by the tumour. This is considered one of the emerging hallmarks of cancer (Hanahan \& Weinberg 2011). It is becoming clearer that distinct infiltrating cell types differ in their prognostic and predictive significance (Fridman et al. 2011). In BC, the intratumoral immune response has an important role in tumour progression, patient relapse and survival, among other processes (de la Cruz-Merino et al. 2013). In particular, tumour-infiltrating lymphocytes (TILs) in BC are of predictive and prognostic value, especially in triple-negative (TN) and human epidermal growth factor receptor (HER) 2-positive BC subtypes (Loi et al. 2019; Salgado et al. 2015). In fact, presence of TILs in the primary tumour significantly impacts the outcome of BC patients, especially when they have ALN metastasis at diagnosis (Loi et al. 2019). Nevertheless, only a few studies have evaluated the impact of either general TILs, by haematoxylin and eosin (H\&E) using Salgado's criteria (Salgado et al. 2015), or specific TIL subtypes in the peritumoral area (or invasive margin), by IHC. Two of them found no significant correlation between peritumoral immune infiltrates and clinical factors (Acs et al. 2017; Al-Saleh et al. 2017).

ALN status at the time of diagnosis is the most important prognostic indicator for women with BC (Bernet Vegue et al. 2012). Moreover, ALN is the place to where the BC most often first disseminates (Valente et al. 2014). There is evidence of immune cell activation in invaded ALNs (Gibert-Ramos et al. 2019), and our group studied non-invaded ALNs of BC patients and identified several immune populations associated with the presence or absence of ALN metastasis at diagnosis (Lopez et al. 2020), also highlighting the importance of the immune response of ALNs to patients' clinical outcome. Some studies have evaluated the possible association of the intratumoral immune response with ALN metastasis, but to our knowledge only one study has shown the peritumoral lymphocytic infiltrate to be an important predictive factor of the metastatic invasion of the ALN (Bordea et al. 2012). It is therefore of utmost importance to know whether the immune response in the peritumoral area of the primary tumour is associated with ALN metastasis in any way. The lack of research on this subject and the issues outlined above prompted us to study the association between the peritumoral immune response and the presence of ALN metastases at diagnosis.

\section{Materials and methods}


109 Tissue preparation and immunohistochemistry

110 This is a retrospective cohort study of 149 patients diagnosed with invasive $\mathrm{BC}$ of no special

111 type in the Hospital de Tortosa Verge de la Cinta (HTVC), Spain, 75 of whom had ALN

112 metastasis at diagnosis. The Ethics Committee of the Hospital Joan XXIII de Tarragona, Spain,

113 approved the study (reference 22p/2011) and we followed the Strengthening the Reporting of

114 Observational Studies in Epidemiology (STROBE) guidelines. Written informed consent was

115 signed by all patients involved in the study, in accordance with Spanish law.

116 Two representative 2-mm tissue cylinders from the border of the tumour area of the biopsy were

117 selected by a pathologist from the Pathology Department of the HTVC for the purpose of

118 constructing tissue microarrays (TMAs). Ductal carcinoma in situ elements and tertiary

119 lymphoid structures around the border of the tumour were excluded when selecting the areas

120 from which cylinders were taken. Each TMA block contained 50 cylinders, giving 6 TMAs ((150

121 patients X 2 cylinders)/50 cylinders). Eleven slides were sectioned from each TMA in order to

122 stain the 11 immune markers chosen for study (Figure 1). TMA technology is of great value for

123 analysing large numbers of cases, but it is clear that the degree of correlation between TMAs and

124 whole-tissue sections is not ideal at the diagnostic level. Nevertheless, the use of TMAs with a

125 large number of samples is widely considered to be adequate for research level (Pinder et al.

126 2013). In fact, as we mentioned in our previous report, in which we also used TMAs (Lopez et

127 al. 2020), a search using the terms "tissue microarray breast cancer immune" in PubMed

128 identified more than 100 articles, highlighting the widespread use of TMAs in studies into the

129 evaluation of the immune system (Pelekanou et al. 2018; Solinas et al. 2017).Moreover, Salgado

130 explained in his guide for evaluating TILs that results in TMAs have proven concordance with

131 those of other studies (Ali et al. 2014; Chavan et al. 2017; Liu et al. 2014; Schalper et al. 2014),

132 which makes them a good option for rapid evaluations (Salgado et al. 2015).

133

134

135

136

137

138

139

140

141

142

The selection of immune markers for the present work was based on the findings of other studies that have demonstrated the various immune cell populations evaluated (lymphocytes, macrophages and the DC) to be associated with BC patient outcome (de Melo Gagliato et al. 2017; Stovgaard et al. 2018; Zhao et al. 2017). Immune cells were immunohistochemically detected on each slide using the following primary antibodies: T helper lymphocytes (anti-CD4, clone 4B12, Dako, Santa Clara, CA, USA), cytotoxic T lymphocytes (anti-CD8, clone C8/144B, Dako, Santa Clara, CA, USA), natural killers (anti-CD57, clone NK1, Zymed, Thermo Fisher Scientific, Waltham, MA, USA), regulatory T cells (anti-FOXP3, clone 236A/E7, CNIO, Madrid, Spain), macrophages (anti-CD68, clone KP1, Dako, Santa Clara, CA, USA), follicular

DC (anti-CD21, clone 1F8, Dako, Santa Clara, CA, USA), Langerhans DC (anti-CDla, clone 143 010, Dako, Santa Clara, CA, USA), plasmacytoid DC (anti-CD123, clone 6H6, eBioscience, San 144 Diego, CA, USA), interdigitant DC (anti-S100, polyclonal, Leica Microsystems GmbH, Wetzlar, 145 Germany), LAMP3 DC+ (anti-CD208, polyclonal, Proteintech, Rosemont, IL, USA), mature DC 146 (anti-CD83, clone1H4b, Leica Microsystems GmbH, Wetzlar, Germany). The ENDVISIONTM

147 FLEX method (Dako, Santa Clara, CA, USA) was applied to stain the slides, using the 
148 chromogen diaminobenzidine (DAB) as a substrate. The samples were counterstained with

149 haematoxylin.

150

\section{Slide digitization and image evaluation}

152 We used whole-slide imaging (WSI), a method that is replacing the microscope for classical 153 diagnosis in some centres (Pantanowitz et al. 2013), to analyse digital images. We obtained the 154 images in TIFF format by scanning the 66 stained slides with an Aperio ScanScope XT scanner 155 at $40 \mathrm{X}$ magnification at a resolution of $0.25 \mu \mathrm{m} /$ pixel. We extracted each cylinder of the original 156 WSI from each TMA as a single image using an automatic tool developed by members of our 157 team (Roszkowiak \& Lopez 2016). The tissue cylinder areas and the stained areas of immune 158 markers in each image were evaluated using our own digital image analysis is procedures (Lopez 159 et al. 2020), which enable the number and density (in $\mu \mathrm{m}^{2}$ ) of pixels of the positive-stained areas 160 for each immune marker, and the area of each cylinder included in the TMAs, to be calculated 161 (Callau et al. 2015). The concentration of each immune marker was calculated as the percentage

\section{Clinical and pathological variables}

166

167

168

169

170

171

172

\section{Statistical analysis}

174

175

176

177

178

179

180

181

182

183

184

To determine which clinical and pathological variables, in addition to the peritumoral immune response, could also be associated with the presence of metastasis in the ALN at diagnosis, the following data were collected from the patients' clinical records: age, tumour diameter, lymphovascular invasion (LVI), perineural invasion (PNI), histological grade, oestrogen receptor status (ER), progesterone receptor status (PR), HER2 status, proliferation index (Ki67), menopausal status and molecular profile.

Differences in immune response marker concentrations between patients diagnosed with and without metastasis in their ALN were evaluated using the Mann-Whitney U test. The quantitative clinical and pathological variables in the two groups of patients were compared using the MannWhitney U test or Student's unmatched samples t-test (age and tumour diameter). In order to identify disproportionate frequencies of combinations of categories of the clinical and pathological variables we performed chi-squared test or Fisher's exact tests.

A univariate logistic regression analysis was carried out for each variable to evaluate its association with the presence or absence of ALNs with metastasis. Two multivariate logistic regression models were then developed to identify which of the clinical and pathological variables, and which of the immune cell populations present in the peritumoral area, were associated with the presence of ALN metastases at diagnosis. The Hosmer-Lemeshow test was

Peer) reviewing PDF | (2020:01:45394:2:0:NEW 28 Jul 2020) 
185 used to estimate the goodness of fit of all the variables considered in the multivariate analyses.

186 The area under the curve (AUC) and the receiver-operating characteristic (ROC) curve were

187 also derived to estimate the sensitivity and specificity of each model. We can consider that the

188 present study, which featured 75 events and yielded final multivariate models comprising three

189 independent variables, had an adequate sample size for a reliable multivariate analysis as

190 previously suggested (Peduzzi et al. 1996). In the first model, all variables with a significance of

$191 \mathrm{p} \leq 0.1$ in the univariate logistic regression analyses were considered when deriving the

192 multivariate model 1 . In the second model, all the variables with a significance of $p \leq 0.3$ were

193 included. Each model was validated using two statistical techniques: (1) bootstrap simulation,

194 carried out with IBM SPSS Statistics 21.0 (IBM, Armonk, NY, USA), based on 10,000 random

195 samples; and (2) the multiple imputation method available in the IBM SPSS statistical

196 application. This method replaces missing values of a specific variable by using linear regression

197 to calculate values from others in the dataset. Failing to deal with missing data is a problem

198 because it leads to a reduction in the statistical power of the model and can produce biased

199 estimates.

200

201 Results

202 Table 1 shows the differences in the clinical and pathological variables between patients with

203 and without metastasis in their ALNs at diagnosis. Patients with metastases in their ALNs have a

204 higher histological grade, more LVI and PNI, and larger-diameter tumours.

205 Table 2 shows the differences in the percentages of the immune populations in the

206 peritumoral regions between patients diagnosed with and without metastatic ALN. There were

207 no differences in the median concentration in the immune populations between the two groups of 208 patients evaluated by the WSI and the digital image procedures.

209 We next identified the variables associated with the presence of metastasis in the ALN at

210 diagnosis from the univariate logistic regressions and using several multivariate logistic

211 regression models. In the first model, we only included those variables that were significant or

212 had a value of $p<0.1$ in the univariate analysis. In this case, only the histological grade and the

213 presence of LVI were independently associated with the presence of ALN metastases at

214 diagnosis (Table 3). None of the immune variables was included in multivariate model 1, as none

215 of the peritumoral immune populations showed any association with ALN metastases at

216 diagnosis or a value of $\mathrm{p}<0.1$ in the univariate model. The Hosmer-Lemeshow test of this first

217 model indicated an excellent goodness of fit to the final model $(\mathrm{p}=0.798)$. Nagelkerke's R-

218 squared was 0.577 , indicating that around $60 \%$ of the variance of the dependent variable

219 (presence of metastasis in the ALN) was explained by the model. The logistic regression model

220 had a sensitivity of $78.4 \%$, a specificity of $86.5 \%$ and an AUC of 0.898 (Figure 2A, black line).

221 The bootstrap validation of multivariate logistic regression model 1 identified tumour diameter

$222(\mathrm{OR}=1.04 ; 95 \% \mathrm{CI}: 1.00-1.07 ; \mathrm{p}=0.026)$, LVI $(\mathrm{OR}=25.42 ; 95 \% \mathrm{CI}: 9.57-67.55 ; \mathrm{p}<0.001)$ and

223 histological grades $2(\mathrm{OR}=3.84$; 95\% CI: $1.11-13.28 ; \mathrm{p}=0.033)$ and 3 (OR=5.18; 95\% CI: $1.40-$

$22419.17 ; \mathrm{p}=0.014)$ as being significant factors. The AUC of validated model 1 was 0.898 , with a 
225

226

227

228

229

230

231

232

233

234

235

236

237

238

239

240

241

242

243

244

245

246

247

248

249

250

251

252

253

254

255

256

257

258

259

260

261

\section{Discussion}

263 In the present study, 11 immune markers in the peritumoral area were examined using WSI,

264 TMA and digital image analysis procedures, to evaluate their association with the presence of

sensitivity of $81.1 \%$ and a specificity of $86.5 \%$ (Figure 2B, black line). All variables included in model 1, illustrated in Table 3, were retained in the validated model, the latter also showing tumour diameter to be associated with metastasis in the ALN at diagnosis (Table 4).

We derived a second multivariate model that included those variables with a level of significance of $p \leq 0.3$ (Table 3 ). The immune populations considered when generating this second model were CD8+ T lymphocytes, CD68+ macrophages, CD1a+ Langerhans DC, S100+ interdigitant DC and CD123+ LAMP3 DC. In the end, the multivariate model comprised only the LVI (with a wider CI than in model 1) and the CD68+ macrophages. Nagelkerke's R-squared was 0.789 , and the Hosmer-Lemeshow test of this second model indicated excellent goodness of fit to the final model $(\mathrm{p}=0.794)$ once again. Compared with model 1 , this second model was more sensitive (88.4\%), less specific $(63.3 \%)$ and had a lower AUC (0.842) (Figure 2A, red line). Nevertheless, the bootstrap validation of model 2 only retained LVI (OR $=24.93 ; 95 \%$ CI: 9.54-65.19) as a significant factor; the CD68+ macrophage factor was dropped. The AUC of this validated model was 0.852 (Figure 2B, red line), with a sensitivity of $78.3 \%$ and specificity of $86.7 \%$.

As an alternative validation system to the first and second models we used multiple imputation for the immune populations. The validation of the first model gave the same results with respect to the OR (Table 4), AUC, sensitivity and specificity as in the unvalidated first model (Figure 2C, black line). After imputing the missing data, none of the immune populations was statistically significant or yielded a value of $\mathrm{p} \leq 0.1$, so the same variables as in model 1 were included for the purpose of validation. In the validation of the second model using a threshold of $\mathrm{p} \leq 0.3$, LVI, histological grade and the tumour diameter were included in the model, but none of immune populations was retained. The validated model had a sensitivity of $79.7 \%$, a specificity of $87.8 \%$ and an AUC of 0.898 (Figure 2C, red line).

To summarize, in three of the four validations of the two models, the histological grade and LVI were factors independently associated with ALN metastasis, and in two of the validations tumour diameter was also included. None of the four validated models featured any of the peritumoral immune populations associated with the presence of ALN metastasis at diagnosis. Only in the second model were CD68+ macrophages associated with ALN metastasis, although even this term was dropped from both validated models (using bootstrapping and multiple imputation methods). With the analysis of our data we mostly observe that the association of CD68 and ALN metastasis (outcome) is not statistically significant and there is more evidence in favour (4 validation + model including variables with $\mathrm{p} \leq 0.1$ ) than against (model including variables with $\mathrm{p} \leq 0.3$ ). Therefore, we assume that the evidence for the association of CD68 and metastasis is not robust enough to conclude that it is a significant variable in our models.

Peer) reviewing PDF | (2020:01:45394:2:0:NEW 28 Jul 2020) 
265

266

267

268

269

270

271

272

273

274

275

276

277

278

279

280

281

282

283

284

285

286

287

288

289

290

291

292

293

294

295

296

297

298

299

300

301

302

303

304

metastasis in the ALN at diagnosis of BC patients. Even though $\mathrm{BC}$ is not a highly immunogenic tumour (Gingras et al. 2015), several studies have demonstrated the importance of the immune response in tumour progression and patient outcome (de la Cruz-Merino et al. 2013; Denkert et al. 2010; Gu-Trantien \& Willard-Gallo 2013; Loi 2013; Loi et al. 2013). Indeed, in TN and HER2-positive BC, TILs are predictive of neoadjuvant therapy and prognostic in patients treated with chemotherapy (Dieci et al. 2018; Loi et al. 2019).

\section{Immune response and ALN metastasis}

In BC, metastasis in ALNs plays a key role in spreading tumoral cells to other parts of the body (Ran et al. 2010); in fact, several types of intratumoral cells are known to be linked to the presence of metastasis in the ALN at diagnosis: cytotoxic and helper T lymphocytes (La Rocca et al. 2008; Matkowski et al. 2009), T regulatory lymphocytes (Gokmen-Polar et al. 2013; Miyan et al. 2016; Nakamura et al. 2009), macrophages (Jubb et al. 2010; Mansfield et al. 2012; Shiota et al. 2016) and dendritic cells (Mansfield et al. 2011; Treilleux et al. 2004). In addition, our group previously found the $\mathrm{CD} 21+$ follicular $\mathrm{DC}$ immune population in the intratumoral region to be associated with the presence of ALN metastasis. In the same study, we compared the immune populations of the non-metastatic ALN in patients diagnosed with or without ALN metastasis. We found that higher concentrations of CD68+ macrophages and of $\mathrm{S} 100+$ interdigitant DC in the non-metastatic ALNs were associated with the presence of ALN metastasis at diagnosis. On the other hand, higher concentrations of CD123+ plasmacytoid DC were found to be a factor protecting against ALN metastasis (Lopez et al. 2020). Since the immune populations could be associated with ALN metastasis in locations other than the intratumoral region, we decided to evaluate the peritumoral area as well.

\section{Peritumoral immune infiltrates in $\mathrm{BC}$}

Little is known about the peritumoral immune infiltrates, and, especially, their links with ALN status. Bordea et al. showed $\mathrm{BC}$ to be more aggressive and associated with an increased rate of sentinel lymph node metastasis in patients with peritumoral TILs (Bordea et al. 2012). However, they did not use H\&E or Salgado's criteria; the latter were published in 2015, and have since become established as the gold standard for TILs assessment (Salgado et al. 2015). Specific types of immune cells have barely been studied in the peritumoral areas of $\mathrm{BC}$ patient samples. CD4+ follicular helper $\mathrm{T}$ cells are associated with peritumoral tertiary lymphoid structures (TLS) (Gu-Trantien et al. 2013). High levels of expression of intratumoral CD8+ TILs are significantly associated with the overall survival (OS) of luminal B patients treated with anthracycline-based neoadjuvant chemotherapy, but the peritumoral fraction is not (Al-Saleh et al. 2017). Conversely, Vgenopoulou et al. investigated peritumoral CD8 and CD57 markers, and found increased numbers of CD8 + cells in ALN+ patients, but no difference in the abundance of the CD57 marker (Vgenopoulou et al. 2003). Liu et al. reported high levels of peritumoral FOXP3+ to be a predictor for chemotherapy of HER2-positive patients. In addition, the latter article is the only one, to our knowledge, to report an association between the immune response in the peritumoral area of the primary tumour and ALN metastasis, showing positive correlation between peritumoral FOXP3+ and positive nodal status (Liu et al. 2014). A study analysing CD68+ 
305

306

307

308

309

310

311

312

313

314

315

316

317

318

319

320

321

322

323

324

325

326

327

328

329

330

331

332

333

334

335

336

337

338

339

340

341

342

343

344

macrophage cells showed that these cells were more likely to be present in the intratumoral area than in the peritumoral area, although its correlation with ALN status was not studied. The study was also limited by its low number of specimens (Carpenco 2019). Controversially, Heiskala et al. found CD68+ infiltrations to be more abundant in the peritumoral than the intratumoral area, but CD68 frequency was not correlated with ALN status (Heiskala et al. 2019). Next, considering DCs, Bell et al. reported immature CD1a+ to be retained intratumorally, and mature CD83+ DCs to be confined to peritumoral areas in patients with BC; nonetheless, the study was performed with only 32 samples and no statistical analyses were carried out (Bell et al. 1999).However, our study revealed no association between the immune infiltrates of the peritumoral area and the presence of ALN metastases at diagnosis, which is in line with the findings of the few studies that have investigated the relation of the immune populations in the peritumoral areas with ALN status.

\section{Clinical and pathological factors associated to ALN metastasis}

Most of the studies on the clinical, molecular and pathological/histological factors associated with ALN metastasis were carried out a long time ago (Ahlgren et al. 1994; Chadha et al. 1994; Noguchi et al. 1993). We found primary tumour size, histological grade and LVI to be histological factors significantly associated with the presence of ALN metastases at diagnosis in two of four validations. These findings are consistent with the well-established pathological characteristics associated with ALN metastasis reviewed by (Patani et al. 2007) and described in subsequent publications (Reynders et al. 2014; Yoshihara et al. 2013). In the present study, model 1 had the best AUC when validated and so had the best predictive capability. The validated first model included the LVI, primary tumour size and histological grade as independent factors associated with having ALN metastasis, and showed very good sensitivity and specificity. Patani et al. highlighted several works showing the values of the sensitivity and specificity of the multivariate models using tumour size, histological grade and LVI (Patani et al. 2007). In some of these studies, sensitivity was related to tumour size, or the histological grade was higher than in our case, but conversely they showed very low specificity (Barth et al. 1997; Reynders et al. 2014; Silverstein et al. 2001). On the other hand, several studies employing models using LVI were very specific but not at all sensitive (Chadha et al. 1994; Tan et al. 2005). Our model gave a very good balance between sensitivity and specificity; in fact, the AUC of the validated first model was almost 0.9 , which implies that our model can correctly classify around $90 \%$ of patients, and shows that these variables are closely associated with the presence of ALN metastasis at diagnosis.

Furthermore, (Tseng et al. 2014) and (Grigoriadis et al. 2018) have demonstrated that other histological features may be associated with the presence of ALN with metastasis at diagnosis (lymphocytic lobulitis, size and number or location of germinal centres, etc.). These variables could also be used to evaluate $\mathrm{BC}$ patient outcome. In fact, another study showed that the presence of CD4+ T cells, localized in the germinal centres of peritumoral TLS found in extensively infiltrated neoplastic lesions, predicted better disease outcome among BC patients (Gu-Trantien \& Willard-Gallo 2013). Indeed, TLS have recently proven to be relevant in 
345 patients' survival and immunotherapy response in other cancer types like sarcoma and melanoma 346 (Cabrita et al. 2020; Helmink et al. 2020; Petitprez et al. 2020). Nevertheless, we did not study 347 the TLS on this occasion, although in the future it would be worthwhile evaluating them in the 348 context of the immune response.

349

350 Conclusions

351 The present study aimed to determine whether the immune response in the peritumoral area of 352 the primary BC tumour was associated with ALN metastasis at diagnosis. We studied 11

353 populations of immune infiltrates in the peritumoral areas by immunohistochemistry and did not 354 find any association with the presence of metastases in the ALNs at diagnosis in BC patients. 355 This does not rule out the possibility that other peritumoral immune populations are associated 356 with ALN metastasis. This matter needs to be studied further, broadening the types of 357 peritumoral immune cells studied and including new peritumoral areas, such as the germinal 358 centres of the peritumoral TLS.

359

\section{Acknowledgements}

361 The authors would like to thank María del Mar Barbera, Anna Curto, Noelia Burgues, Ainhoa 362 Montserrat, Eduard Nolla, Maria Fortuny, Sandra Bages, Mireia Sueca and Marc Iniesta for their 363 skilful technical assistance, and Anna Carot her excellent secretarial work. 


\section{References}

365

366

367

368

369

370

371

372

373

374

375

376

377

378

379

380

381

382

383

384

385

386

387

388

389

390

391

392

393

394

395

396

397

398

399

400

401

402

403

404

405

406

407

408
Acs B, Madaras L, Tokes AM, Kovacs AK, Kovacs E, Ozsvari-Vidakovich M, Karaszi A, Birtalan E, Dank M, Szasz AM, and Kulka J. 2017. PD-1, PD-L1 and CTLA-4 in pregnancy-related - and in early-onset breast cancer: A comparative study. Breast 35:69-77. 10.1016/j.breast.2017.06.013

Ahlgren J, Stal O, Westman G, and Arnesson LG. 1994. Prediction of axillary lymph node metastases in a screened breast cancer population. South-East Sweden Breast Cancer Group. Acta Oncol 33:603-608. 10.3109/02841869409121769

Al-Saleh K, Abd El-Aziz N, Ali A, Abozeed W, Abd El-Warith A, Ibraheem A, Ansari J, Al-Rikabi A, Husain S, and Nabholtz JM. 2017. Predictive and prognostic significance of $\mathrm{CD} 8(+)$ tumor-infiltrating lymphocytes in patients with luminal B/HER 2 negative breast cancer treated with neoadjuvant chemotherapy. Oncol Lett 14:337-344. 10.3892/ol.2017.6144

Ali HR, Provenzano E, Dawson SJ, Blows FM, Liu B, Shah M, Earl HM, Poole CJ, Hiller L, Dunn JA, Bowden SJ, Twelves C, Bartlett JM, Mahmoud SM, Rakha E, Ellis IO, Liu S, Gao D, Nielsen TO, Pharoah PD, and Caldas C. 2014. Association between CD8+ T-cell infiltration and breast cancer survival in 12,439 patients. Ann Oncol 25:1536-1543. 10.1093/annonc/mdu191

Barth A, Craig PH, and Silverstein MJ. 1997. Predictors of axillary lymph node metastases in patients with T1 breast carcinoma. Cancer 79:1918-1922.

Bell D, Chomarat P, Broyles D, Netto G, Harb GM, Lebecque S, Valladeau J, Davoust J, Palucka KA, and Banchereau J. 1999. In breast carcinoma tissue, immature dendritic cells reside within the tumor, whereas mature dendritic cells are located in peritumoral areas. J Exp Med 190:1417-1426. 10.1084/jem.190.10.1417

Bernet Vegue L, Cano Munoz R, and Pinero Madrona A. 2012. Breast cancer sentinel lymph node and axillary lymphadenectomy: New tools for new challenges. Expert Rev Mol Diagn 12:147-158. 10.1586/erm.11.96

Bordea C, Bordea M, Totan A, Condrea I, Voinea S, Sandru A, Plesca M, and Blidaru A. 2012. Immunological aspects predicting metastatic sentinel lymph node in early breast cancer patients. J Med Life 5:455-461.

Cabrita R, Lauss M, Sanna A, Donia M, Skaarup Larsen M, Mitra S, Johansson I, Phung B, Harbst K, Vallon-Christersson J, van Schoiack A, Lovgren K, Warren S, Jirstrom K, Olsson H, Pietras K, Ingvar C, Isaksson K, Schadendorf D, Schmidt H, Bastholt L, Carneiro A, Wargo JA, Svane IM, and Jonsson G. 2020. Tertiary lymphoid structures improve immunotherapy and survival in melanoma. Nature 577:561-565. 10.1038/s41586-019-1914-8

Callau C, Lejeune M, Korzynska A, Garcia M, Bueno G, Bosch R, Jaen J, Orero G, Salvado T, and Lopez C. 2015. Evaluation of cytokeratin-19 in breast cancer tissue samples: a comparison of automatic and manual evaluations of scanned tissue microarray cylinders. Biomed Eng Online 14 Suppl 2:S2. 10.1186/1475925X-14-S2-S2

Carpenco E. 2019. Tumor associated macrophages in breast cancer. Moldovan Medical Journal 62:24-27. 10.5281/zenodo.2590003

Corthay A. 2014. Does the immune system naturally protect against cancer? Front Immunol 5:197. 10.3389/fimmu.2014.00197 
409

410

411

412

413

414

415

416

417

418

419

420

421

422

423

424

425

426

427

428

429

430

431

432

433

434

435

436

437

438

439

440

441

442

443

444

445

446

447

448

449

450

451

452

Chadha M, Chabon AB, Friedmann P, and Vikram B. 1994. Predictors of axillary lymph node metastases in patients with $\mathrm{T} 1$ breast cancer. A multivariate analysis.

Cancer 73:350-353. 10.1002/1097-0142(19940115)73:2<350::aidcncr2820730219>3.0.co;2-5

Chavan SS, Ravindra S, and Prasad M. 2017. Breast biomarkers-comparison on whole section and tissue microarray section. J Clin Diagn Res 11:EC40-EC44. 10.7860/JCDR/2017/25088.9573

de la Cruz-Merino L, Barco-Sanchez A, Henao Carrasco F, Nogales Fernandez E, Vallejo Benitez A, Brugal Molina J, Martinez Peinado A, Grueso Lopez A, Ruiz Borrego M, Codes Manuel de Villena M, Sanchez-Margalet V, Nieto-Garcia A, Alba Conejo E, Casares Lagar N, and Ibanez Martinez J. 2013. New insights into the role of the immune microenvironment in breast carcinoma. Clin Dev Immunol 2013:785317. 10.1155/2013/785317

de Melo Gagliato D, Cortes J, Curigliano G, Loi S, Denkert C, Perez-Garcia J, and Holgado E. 2017. Tumor-infiltrating lymphocytes in breast cancer and implications for clinical practice. Biochim Biophys Acta Rev Cancer 1868:527537. 10.1016/j.bbcan.2017.10.003

Denkert C, Loibl S, Noske A, Roller M, Muller BM, Komor M, Budczies J, Darb-Esfahani S, Kronenwett R, Hanusch C, von Torne C, Weichert W, Engels K, Solbach C, Schrader I, Dietel M, and von Minckwitz G. 2010. Tumor-associated lymphocytes as an independent predictor of response to neoadjuvant chemotherapy in breast cancer. J Clin Oncol 28:105-113. 10.1200/JCO.2009.23.7370

Dieci MV, Radosevic-Robin N, Fineberg S, van den Eynden G, Ternes N, PenaultLlorca F, Pruneri G, D'Alfonso TM, Demaria S, Castaneda C, Sanchez J, Badve S, Michiels S, Bossuyt V, Rojo F, Singh B, Nielsen T, Viale G, Kim SR, Hewitt S, Wienert S, Loibl S, Rimm D, Symmans F, Denkert C, Adams S, Loi S, and Salgado R. 2018. Update on tumor-infiltrating lymphocytes (TILs) in breast cancer, including recommendations to assess TILs in residual disease after neoadjuvant therapy and in carcinoma in situ: A report of the International Immuno-Oncology Biomarker Working Group on Breast Cancer. Semin Cancer Biol 52:16-25. 10.1016/j.semcancer.2017.10.003

Fridman WH, Galon J, Pages F, Tartour E, Sautes-Fridman C, and Kroemer G. 2011. Prognostic and predictive impact of intra- and peritumoral immune infiltrates. Cancer Res 71:5601-5605. 10.1158/0008-5472.CAN-11-1316

Gardner A, and Ruffell B. 2016. Dendritic cells and cancer immunity. Trends Immunol 37:855-865. 10.1016/j.it.2016.09.006

Gibert-Ramos A, Lopez C, Bosch R, Fontoura L, Bueno G, Garcia-Rojo M, Berenguer $M$, and Lejeune M. 2019. Immune response profile of primary tumour, sentinel and non-sentinel axillary lymph nodes related to metastasis in breast cancer: An immunohistochemical point of view. Histochem Cell Biol 152:177-193. 10.1007/s00418-019-01802-7

Gingras I, Azim HA, Jr., Ignatiadis M, and Sotiriou C. 2015. Immunology and breast cancer: toward a new way of understanding breast cancer and developing novel therapeutic strategies. Clin Adv Hematol Oncol 13:372-382.

Peer) reviewing PDF | (2020:01:45394:2:0:NEW 28 Jul 2020) 
453 Gokmen-Polar Y, Thorat MA, Sojitra P, Saxena R, and Badve S. 2013. FOXP3

454

455

456

457

458

459

460

461

462

463

464

465

466

467

468

469

470

471

472

473

474

475

476

477

478

479

480

481

482

483

484

485

486

487

488

489

490

491

492

493

494

495

496

497

expression and nodal metastasis of breast cancer. Cell Oncol (Dordr) 36:405-

409. 10.1007/s13402-013-0147-3

Grigoriadis A, Gazinska P, Pai T, Irhsad S, Wu Y, Millis R, Naidoo K, Owen J, Gillett CE, Tutt A, Coolen AC, and Pinder SE. 2018. Histological scoring of immune and stromal features in breast and axillary lymph nodes is prognostic for distant metastasis in lymph node-positive breast cancers. J Pathol Clin Res 4:39-54. $10.1002 / \mathrm{cjp} 2.87$

Gu-Trantien C, Loi S, Garaud S, Equeter C, Libin M, de Wind A, Ravoet M, Le Buanec H, Sibille C, Manfouo-Foutsop G, Veys I, Haibe-Kains B, Singhal SK, Michiels S, Rothe F, Salgado R, Duvillier H, Ignatiadis M, Desmedt C, Bron D, Larsimont D, Piccart M, Sotiriou C, and Willard-Gallo K. 2013. CD4(+) follicular helper T cell infiltration predicts breast cancer survival. J Clin Invest 123:2873-2892. $10.1172 / \mathrm{JCl} 67428$

Gu-Trantien C, and Willard-Gallo K. 2013. Tumor-infiltrating follicular helper T cells: The new kids on the block. Oncoimmunology 2:e26066. 10.4161/onci.26066

Hanahan D, and Coussens LM. 2012. Accessories to the crime: Functions of cells recruited to the tumor microenvironment. Cancer Cell 21:309-322. 10.1016/j.ccr.2012.02.022

Hanahan D, and Weinberg RA. 2011. Hallmarks of cancer: The next generation. Cell 144:646-674. 10.1016/j.cell.2011.02.013

Heiskala M, Leidenius M, Joensuu K, and Heikkila P. 2019. High expression of CCL2 in tumor cells and abundant infiltration with CD14 positive macrophages predict early relapse in breast cancer. Virchows Arch 474:3-12. 10.1007/s00428-0182461-7

Helmink BA, Reddy SM, Gao J, Zhang S, Basar R, Thakur R, Yizhak K, Sade-Feldman M, Blando J, Han G, Gopalakrishnan V, Xi Y, Zhao H, Amaria RN, Tawbi HA, Cogdill AP, Liu W, LeBleu VS, Kugeratski FG, Patel S, Davies MA, Hwu P, Lee JE, Gershenwald JE, Lucci A, Arora R, Woodman S, Keung EZ, Gaudreau PO, Reuben A, Spencer CN, Burton EM, Haydu LE, Lazar AJ, Zapassodi R, Hudgens CW, Ledesma DA, Ong S, Bailey M, Warren S, Rao D, Krijgsman O, Rozeman EA, Peeper D, Blank CU, Schumacher TN, Butterfield LH, Zelazowska MA, McBride KM, Kalluri R, Allison J, Petitprez F, Fridman WH, Sautes-Fridman C, Hacohen N, Rezvani K, Sharma P, Tetzlaff MT, Wang L, and Wargo JA. 2020. B cells and tertiary lymphoid structures promote immunotherapy response. Nature 577:549-555. 10.1038/s41586-019-1922-8

Jubb AM, Soilleux EJ, Turley H, Steers G, Parker A, Low I, Blades J, Li JL, Allen P, Leek R, Noguera-Troise I, Gatter KC, Thurston G, and Harris AL. 2010. Expression of vascular notch ligand delta-like 4 and inflammatory markers in breast cancer. Am J Pathol 176:2019-2028. 10.2353/ajpath.2010.090908

La Rocca G, Anzalone R, Corrao S, Magno F, Rappa F, Marasa S, Czarnecka AM, Marasa L, Sergi C, Zummo G, and Cappello F. 2008. CD1a down-regulation in primary invasive ductal breast carcinoma may predict regional lymph node invasion and patient outcome. Histopathology 52:203-212. 10.1111/j.13652559.2007.02919.x

Peer) reviewing PDF | (2020:01:45394:2:0:NEW 28 Jul 2020) 
498

499

500

501

502

503

504

505

506

507

508

509

510

511

512

513

514

515

516

517

518

519

520

521

522

523

524

525

526

527

528

529

530

531

532

533

534

535

536

537

538

539

540

541

542

543
Liu S, Foulkes WD, Leung S, Gao D, Lau S, Kos Z, and Nielsen TO. 2014. Prognostic significance of FOXP3+ tumor-infiltrating lymphocytes in breast cancer depends on estrogen receptor and human epidermal growth factor receptor-2 expression status and concurrent cytotoxic T-cell infiltration. Breast Cancer Res 16:432. 10.1186/s13058-014-0432-8

Loi S. 2013. Tumor-infiltrating lymphocytes, breast cancer subtypes and therapeutic efficacy. Oncolmmunology 2:e24720. 10.4161/onci.24720

Loi S, Drubay D, Adams S, Pruneri G, Francis PA, Lacroix-Triki M, Joensuu H, Dieci MV, Badve S, Demaria S, Gray R, Munzone E, Lemonnier J, Sotiriou C, Piccart MJ, Kellokumpu-Lehtinen PL, Vingiani A, Gray K, Andre F, Denkert C, Salgado $\mathrm{R}$, and Michiels S. 2019. Tumor-infiltrating lymphocytes and prognosis: A pooled individual patient analysis of early-stage triple-negative breast cancers. J Clin Oncol 37:559-569. 10.1200/JCO.18.01010

Loi S, Sirtaine N, Piette F, Salgado R, Viale G, Van Eenoo F, Rouas G, Francis P, Crown JP, Hitre E, de Azambuja E, Quinaux E, Di Leo A, Michiels S, Piccart MJ, and Sotiriou C. 2013. Prognostic and predictive value of tumor-infiltrating lymphocytes in a phase III randomized adjuvant breast cancer trial in nodepositive breast cancer comparing the addition of docetaxel to doxorubicin with doxorubicin-based chemotherapy: BIG 02-98. J Clin Oncol 31:860-867. 10.1200/JCO.2011.41.0902

Lopez C, Bosch R, Orero G, Korzynska A, Garcia-Rojo M, Bueno G, FernandezCarrobles MDM, Gibert-Ramos A, Roszkowiak L, Callau C, Fontoura L, Salvado MT, Alvaro T, Jaen J, Roso-Llorach A, Llobera M, Gil J, Onyos M, Plancoulaine $B$, Baucells J, and Lejeune M. 2020. The immune response in nonmetastatic axillary lymph nodes is associated with the presence of axillary metastasis and breast cancer patient outcome. Am J Pathol 190:660-673.

10.1016/j.ajpath.2019.11.002

Mansfield AS, Heikkila P, von Smitten K, Vakkila J, and Leidenius M. 2011. Metastasis to sentinel lymph nodes in breast cancer is associated with maturation arrest of dendritic cells and poor co-localization of dendritic cells and CD8+ T cells. Virchows Arch 459:391-398. 10.1007/s00428-011-1145-3

Mansfield AS, Heikkila P, von Smitten K, Vakkila J, and Leidenius M. 2012. The presence of sinusoidal CD163(+) macrophages in lymph nodes is associated with favorable nodal status in patients with breast cancer. Virchows Arch 461:639-646. 10.1007/s00428-012-1338-4

Matkowski R, Gisterek I, Halon A, Lacko A, Szewczyk K, Staszek U, Pudelko M, Szynglarewicz B, Szelachowska J, Zolnierek A, and Kornafel J. 2009. The prognostic role of tumor-infiltrating CD4 and CD8 T lymphocytes in breast cancer. Anticancer Res 29:2445-2451.

Miyan M, Schmidt-Mende J, Kiessling R, Poschke I, and de Boniface J. 2016. Differential tumor infiltration by T-cells characterizes intrinsic molecular subtypes in breast cancer. J Trans/ Med 14:227. 10.1186/s12967-016-0983-9

Nakamura R, Sakakibara M, Nagashima T, Sangai T, Arai M, Fujimori T, Takano S, Shida T, Nakatani Y, and Miyazaki M. 2009. Accumulation of regulatory T cells in sentinel lymph nodes is a prognostic predictor in patients with node-negative breast cancer. Eur J Cancer 45:2123-2131. 10.1016/j.ejca.2009.03.024 
544 Noguchi M, Thomas M, Kitagawa H, Kinishita K, Kinami S, Takamura H, Miyazaki I, and

545

546

547

548

549

550

551

552

553

554

555

556

557

558

559

560

561

562

563

564

565

566

567

568

569

570

571

572

573

574

575

576

577

578

579

580

581

582

583

584

585

586

587

588

589

Mizukami Y. 1993. DNA ploidy and helix pomatia lectin binding as predictors of regional lymph node metastases and prognostic factors in breast cancer. Breast Cancer Res Treat 26:67-75. 10.1007/bf00682701

Pantanowitz L, Sinard JH, Henricks WH, Fatheree LA, Carter AB, Contis L, Beckwith BA, Evans AJ, Lal A, and Parwani AV. 2013. Validating whole slide imaging for diagnostic purposes in pathology: guideline from the College of American Pathologists Pathology and Laboratory Quality Center. Arch Pathol Lab Med 137:1710-1722. 10.5858/arpa.2013-0093-CP

Patani NR, Dwek MV, and Douek M. 2007. Predictors of axillary lymph node metastasis in breast cancer: A systematic review. Eur J Surg Oncol 33:409-419. 10.1016/j.ejso.2006.09.003

Peduzzi P, Concato J, Kemper E, Holford TR, and Feinstein AR. 1996. A simulation study of the number of events per variable in logistic regression analysis. $J$ Clin Epidemiol 49:1373-1379.

Pelekanou V, Villarroel-Espindola F, Schalper KA, Pusztai L, and Rimm DL. 2018. CD68, CD163, and matrix metalloproteinase 9 (MMP-9) co-localization in breast tumor microenvironment predicts survival differently in ER-positive and -negative cancers. Breast Cancer Res 20:154. 10.1186/s13058-018-1076-x

Petitprez F, de Reynies A, Keung EZ, Chen TW, Sun CM, Calderaro J, Jeng YM, Hsiao LP, Lacroix L, Bougouin A, Moreira M, Lacroix G, Natario I, Adam J, Lucchesi C, Laizet YH, Toulmonde M, Burgess MA, Bolejack V, Reinke D, Wani KM, Wang WL, Lazar AJ, Roland CL, Wargo JA, Italiano A, Sautes-Fridman C, Tawbi HA, and Fridman WH. 2020. B cells are associated with survival and immunotherapy response in sarcoma. Nature 577:556-560. 10.1038/s41586-019-1906-8

Pinder SE, Brown JP, Gillett C, Purdie CA, Speirs V, Thompson AM, and Shaaban AM. 2013. The manufacture and assessment of tissue microarrays: Suggestions and criteria for analysis, with breast cancer as an example. J Clin Pathol 66:169-177. 10.1136/jclinpath-2012-201091

Ran S, Volk L, Hall K, and Flister MJ. 2010. Lymphangiogenesis and lymphatic metastasis in breast cancer. Pathophysiology 17:229-251.

10.1016/j.pathophys.2009.11.003

Reynders A, Brouckaert O, Smeets A, Laenen A, Yoshihara E, Persyn F, Floris G, Leunen K, Amant F, Soens J, Van Ongeval C, Moerman P, Vergote I, Christiaens MR, Staelens G, Van Eygen K, Vanneste A, Van Dam P, Colpaert C, and Neven P. 2014. Prediction of non-sentinel lymph node involvement in breast cancer patients with a positive sentinel lymph node. Breast 23:453-459. 10.1016/j.breast.2014.03.009

Roszkowiak L, and Lopez C. 2016. PATMA: Parser of archival tissue microarray. PeerJ 4:e2741. 10.7717/peerj.2741

Salgado R, Denkert C, Demaria S, Sirtaine N, Klauschen F, Pruneri G, Wienert S, Van den Eynden G, Baehner FL, Penault-Llorca F, Perez EA, Thompson EA, Symmans WF, Richardson AL, Brock J, Criscitiello C, Bailey H, Ignatiadis M, Floris G, Sparano J, Kos Z, Nielsen T, Rimm DL, Allison KH, Reis-Filho JS, Loibl S, Sotiriou C, Viale G, Badve S, Adams S, Willard-Gallo K, and Loi S. 2015. The evaluation of tumor-infiltrating lymphocytes (TILs) in breast cancer:

Peer) reviewing PDF | (2020:01:45394:2:0:NEW 28 Jul 2020) 
590

591

592

593

594

595

596

597

598

599

600

601

602

603

604

605

606

607

608

609

610

611

612

613

614

615

616

617

618

619

620

621

622

623

624

625

626

627

628

629

630

631

632

633

634

Recommendations by an International TILs Working Group 2014. Ann Oncol 26:259-271. 10.1093/annonc/mdu450

Schalper KA, Velcheti V, Carvajal D, Wimberly H, Brown J, Pusztai L, and Rimm DL. 2014. In situ tumor PD-L1 mRNA expression is associated with increased TILs and better outcome in breast carcinomas. Clin Cancer Res 20:2773-2782. 10.1158/1078-0432.CCR-13-2702

Shiota T, Miyasato Y, Ohnishi K, Yamamoto-Ibusuki M, Yamamoto Y, Iwase H, Takeya M, and Komohara Y. 2016. The clinical significance of CD169-positive lymph node macrophage in patients with breast cancer. PLoS One 11:e0166680. 10.1371/journal.pone. 0166680

Siegel RL, Miller KD, and Jemal A. 2017. Cancer statistics, 2017. CA Cancer J Clin 67:7-30. 10.3322/caac. 21387

Silverstein MJ, Skinner KA, and Lomis TJ. 2001. Predicting axillary nodal positivity in 2282 patients with breast carcinoma. World J Surg 25:767-772. 10.1007/s00268001-0003-X

Solinas C, Garaud S, De Silva P, Boisson A, Van den Eynden G, de Wind A, Risso P, Rodrigues Vitoria J, Richard F, Migliori E, Noel G, Duvillier H, Craciun L, Veys I, Awada A, Detours V, Larsimont D, Piccart-Gebhart M, and Willard-Gallo K. 2017. Immune checkpoint molecules on tumor-infiltrating lymphocytes and their association with tertiary lymphoid structures in human breast cancer. Front Immunol 8:1412. 10.3389/fimmu.2017.01412

Stovgaard ES, Nielsen D, Hogdall E, and Balslev E. 2018. Triple negative breast cancer - prognostic role of immune-related factors: A systematic review. Acta Oncol 57:74-82. 10.1080/0284186X.2017.1400180

Tan LG, Tan YY, Heng D, and Chan MY. 2005. Predictors of axillary lymph node metastases in women with early breast cancer in Singapore. Singapore Med $J$ 46:693-697.

Treilleux I, Blay JY, Bendriss-Vermare N, Ray-Coquard I, Bachelot T, Guastalla JP, Bremond A, Goddard S, Pin JJ, Barthelemy-Dubois C, and Lebecque S. 2004. Dendritic cell infiltration and prognosis of early stage breast cancer. Clin Cancer Res 10:7466-7474. 10.1158/1078-0432.CCR-04-0684

Tseng HS, Chen LS, Kuo SJ, Chen ST, Wang YF, and Chen DR. 2014. Tumor characteristics of breast cancer in predicting axillary lymph node metastasis. Med Sci Monit 20:1155-1161. 10.12659/MSM.890491

Valente AL, Kane JL, Ellsworth DL, Shriver CD, and Ellsworth RE. 2014. Molecular response of the axillary lymph node microenvironment to metastatic colonization. Clin Exp Metastasis 31:565-572. 10.1007/s10585-014-9650-9

Vgenopoulou S, Lazaris AC, Markopoulos C, Boltetsou E, Kyriakou V, Kavantzas N, Patsouris E, and Davaris PS. 2003. Immunohistochemical evaluation of immune response in invasive ductal breast cancer of not-otherwise-specified type. Breast 12:172-178. 10.1016/s0960-9776(03)00004-3

Weber CE, and Kuo PC. 2012. The tumor microenvironment. Surg Oncol 21:172-177. 10.1016/j.suronc.2011.09.001

Yoshihara E, Smeets A, Laenen A, Reynders A, Soens J, Van Ongeval C, Moerman P, Paridaens R, Wildiers H, Neven P, and Christiaens MR. 2013. Predictors of

Peer) reviewing PDF | (2020:01:45394:2:0:NEW 28 Jul 2020) 
635 axillary lymph node metastases in early breast cancer and their applicability in $636 \quad$ clinical practice. Breast 22:357-361. 10.1016/j.breast.2012.09.003

637 Zhao X, Qu J, Sun Y, Wang J, Liu X, Wang F, Zhang H, Wang W, Ma X, Gao X, and 638 Zhang S. 2017. Prognostic significance of tumor-associated macrophages in 639 breast cancer: A meta-analysis of the literature. Oncotarget 8:30576-30586.

$640 \quad 10.18632$ /oncotarget.15736

641

642 


\section{Figure 1}

Immunohistochemical staining patterns of immune markers in formalin-fixed, paraffinembedded sections.

Representative examples of membrane (A) CD4, (B) CD8, (C) CD21, cytoplasmic (D) CD68, (E) CD123, (F) LAMP3, membrane and/or cytoplasmic (G) CD57, (H) CD1a, (I) CD83, nuclear and/or cytoplasmic (J) S100 and nuclear (K) FOXP3 reactivity of the biomarkers (magnification 20X). 

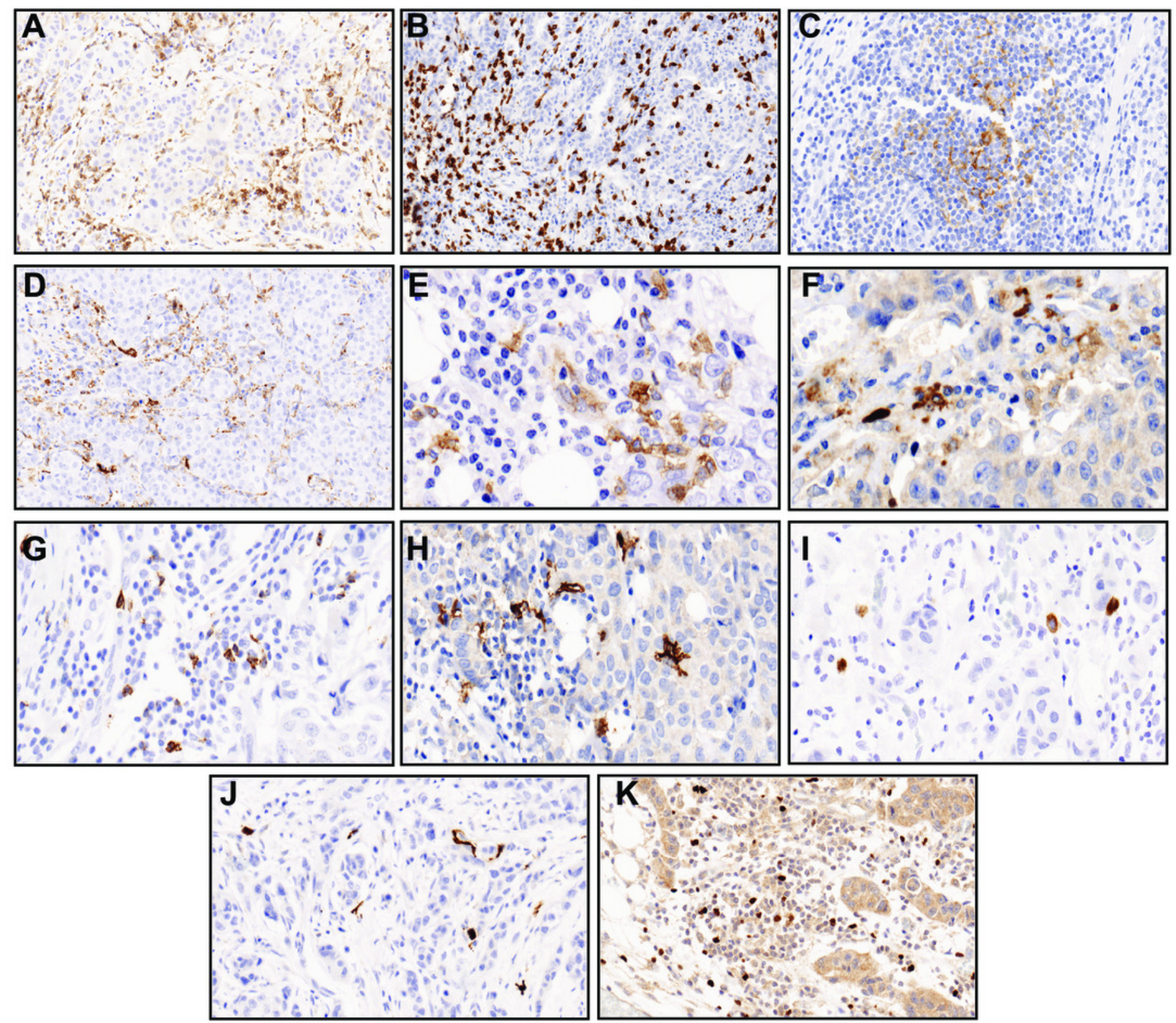
Figure 2

Receiver-operating characteristic (ROC) curves.

ROC curves of $(A)$ the two multivariate logistic regression models; $(B)$ the two validated multivariate logistic regression models derived by the bootstrap method; and (C) the two validated multivariate logistic regression models derived by multiple imputation. Values of the area under the curve (AUC) and the 95\% confidence interval $(\mathrm{Cl})$ for each original model and validated model are presented.
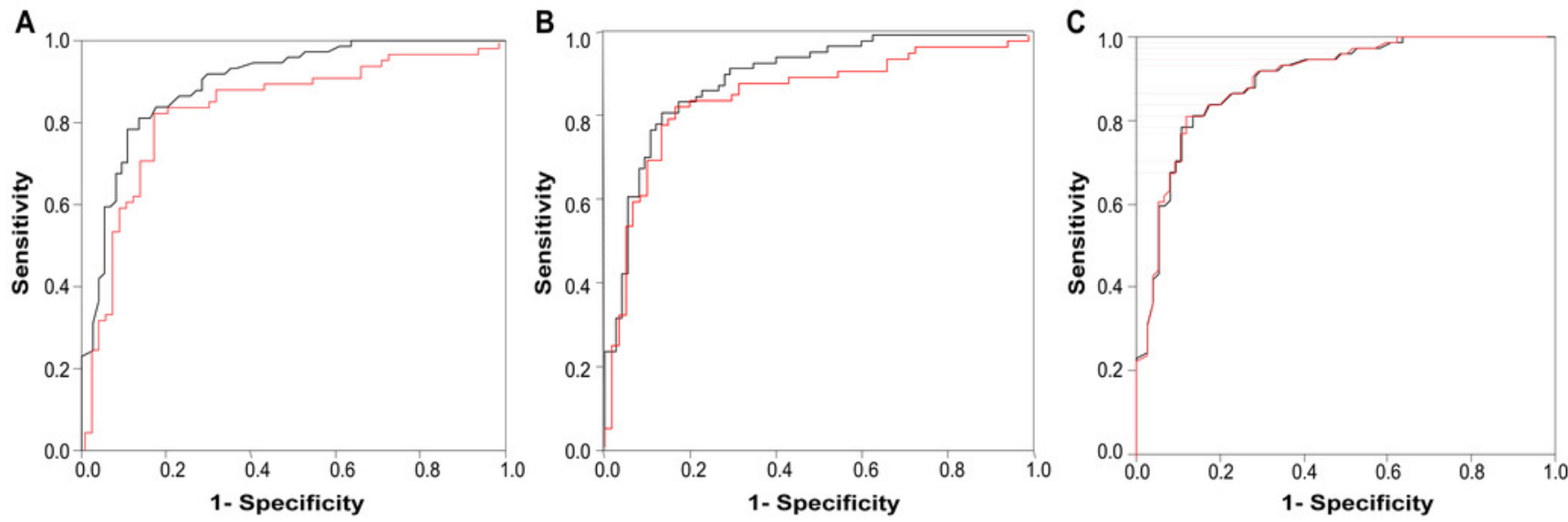

\begin{tabular}{|l|ll|}
\hline \multicolumn{3}{|c|}{ Logistic regression } \\
\hline \multirow{3}{*}{ AUC } & Model 1 & Model 2 \\
\cline { 2 - 3 } CI (95\%) & 0.898 & 0.842 \\
Sensitivity & $0.847-0.948$ & $0.770-0.913$ \\
Specificity & 0.784 & 0.884 \\
& 0.865 & 0.633 \\
\hline
\end{tabular}

\begin{tabular}{|c|c|c|}
\hline \multicolumn{3}{|c|}{ Bootstrap } \\
\hline & Model 1 & Model 2 \\
\hline AUC & 0.898 & 0.852 \\
\hline $\mathrm{Cl}(95 \%)$ & $0.848-0.947$ & $0.771-0.915$ \\
\hline Sensitivity & 0.811 & 0.783 \\
\hline Specificity & 0.865 & 0.867 \\
\hline
\end{tabular}

\begin{tabular}{|l|ll|}
\hline \multicolumn{3}{|c|}{ Multiple imputation for missing data } \\
\hline \multirow{2}{*}{ AUC } & Model 1 & Model 2 \\
\cline { 2 - 3 } CI $(95 \%)$ & 0.898 & 0.898 \\
Sensitivity & $0.847-0.948$ & $0.848-0.948$ \\
Specificity & 0.864 & 0.797 \\
\end{tabular}




\section{Table $\mathbf{1}$ (on next page)}

Differences in the clinical and pathological variables between patients with and without $\mathrm{ALN}^{+}$at diagnosis.

$\mathrm{ALN}^{+}=$metastatic axillary lymph node. $\mathrm{LVI}=$ lymphovascular invasion. $\mathrm{PNI}=$ perineural invasion. $\mathrm{ER}=$ oestrogen receptor. $\mathrm{PR}=$ progesterone receptor. $\mathrm{HER}=$ human epidermal growth factor receptor. The data and statistical tests summarised in the table are the mean (standard deviation) for the t-Student test ${ }^{\dagger}$, the median (interquartile range) for the MannWhitney $U$ test $^{\ddagger}$, and the number of patients (percentage) in each category for the chisquared or Fisher's exact test*. 


\begin{tabular}{|c|c|c|c|}
\hline & $\begin{array}{c}\text { Patients } \\
\text { without ALN } \\
\text { at diagnosis } \\
(n=74)\end{array}$ & $\begin{array}{c}\text { Patients with } \\
\text { ALN }{ }^{+} \text {at } \\
\text { diagnosis } \\
(n=75)\end{array}$ & $\mathbf{p}$ \\
\hline Age (years) & $61.3(10.7)$ & $59.7(12.0)$ & $0.394^{\dagger}$ \\
\hline Tumour diameter (mm) & $15.0(12.3)$ & $22.0(13.0)$ & $<0.001^{\ddagger}$ \\
\hline \multicolumn{4}{|l|}{ LVI } \\
\hline Yes & $9(12.2 \%)$ & $57(77.0 \%)$ & $<0.001^{*}$ \\
\hline No & $65(87.8 \%)$ & $17(23.0 \%)$ & \\
\hline \multicolumn{4}{|l|}{ PNI } \\
\hline Yes & $10(13.5 \%)$ & $30(40.5 \%)$ & $<0.001^{*}$ \\
\hline No & $64(86.5 \%)$ & $44(59.5 \%)$ & \\
\hline \multicolumn{4}{|l|}{ Histological grade } \\
\hline 1 & $27(36.5 \%)$ & $8(10.7 \%)$ & $<0.001^{*}$ \\
\hline 2 & 30 (40.5\%) & $34(45.3 \%)$ & \\
\hline 3 & $17(23.0 \%)$ & $33(44.0 \%)$ & \\
\hline \multicolumn{4}{|l|}{ ER expression } \\
\hline Positive & $55(74.3 \%)$ & $53(70.7 \%)$ & $0.617^{*}$ \\
\hline Negative & $19(25.7 \%)$ & $22(29.3 \%)$ & \\
\hline \multicolumn{4}{|l|}{ PR expression } \\
\hline Positive & $50(67.6 \%)$ & $41(54.7 \%)$ & $0.106^{*}$ \\
\hline Negative & $24(32.4 \%)$ & $34(45.3 \%)$ & \\
\hline \multicolumn{4}{|l|}{ HER-2 amplification } \\
\hline Amplified & $18(24.7 \%)$ & $20(26.7 \%)$ & $0.780^{*}$ \\
\hline Non-amplified & $55(75.3 \%)$ & $55(73.3 \%)$ & \\
\hline \multicolumn{4}{|l|}{ Ki 67 degree } \\
\hline Low & $26(35.1 \%)$ & $16(21.9 \%)$ & $0.120^{*}$ \\
\hline Medium & $26(35.1 \%)$ & $25(34.3 \%)$ & \\
\hline High & $22(29.8 \%)$ & $32(43.8 \%)$ & \\
\hline \multicolumn{4}{|l|}{ Menopausal status } \\
\hline Pre-menopausal & $8(11.6 \%)$ & $15(22.1 \%)$ & $0.101^{*}$ \\
\hline Post-menopausal & $61(88.4 \%)$ & $53(77.9 \%)$ & \\
\hline \multicolumn{4}{|l|}{ Molecular profile } \\
\hline Luminal A & $47(64.3 \%)$ & $46(61.4 \%)$ & $0.967^{*}$ \\
\hline Luminal B & $10(13.7 \%)$ & $10(13.3 \%)$ & \\
\hline HER-2 & $8(11.0 \%)$ & $10(13.3 \%)$ & \\
\hline Triple-negative & $8(11.0 \%)$ & $9(12.0 \%)$ & \\
\hline
\end{tabular}




\section{Table 2 (on next page)}

Differences in the percentages of the immune populations in the peritumoral regions between patients diagnosed with and without $\mathrm{ALN}^{+}$.

$\mathrm{ALN}^{+}=$metastatic axillary lymph node. The values in the table are the median (interquartile range) of the percentage of positive area expressed for each marker. The differences between groups were evaluated using the Mann-Whitney $\mathrm{U}$ test. 


\begin{tabular}{rlccc}
\cline { 2 - 5 } 1 & & $\begin{array}{c}\text { Patients } \\
\text { without ALN } \\
\text { at diagnosis } \\
(\mathbf{n = 7 4 )}\end{array}$ & $\begin{array}{c}\text { Patients with } \\
\mathbf{A L N}^{+} \text {at } \\
\text { diagnosis } \\
(\mathbf{n = 7 5 )}\end{array}$ & $\mathbf{p}$ \\
3 & & Peritumoral & \\
\cline { 2 - 5 } 4 & CD4 & $1.6(3.4)$ & $1.7(3.6)$ & 0.782 \\
5 & CD8 & $1.4(2.8)$ & $2.0(3.3)$ & 0.386 \\
6 & CD57 & $0.2(0.5)$ & $0.3(0.8)$ & 0.099 \\
7 & CDXP3 & $0.1(0.2)$ & $0.1(0.2)$ & 0.598 \\
7 & CD68 & $0.000(0.005)$ & $0.000(0.001)$ & 0.405 \\
8 & CD1a & $2.4(2.3)$ & $2.7(3.0)$ & 0.221 \\
9 & CD123 & $0.1(0.3)$ & $0.1(0.2)$ & 0.133 \\
10 & S100 & $0.00(0.09)$ & $0.00(0.08)$ & 0.377 \\
11 & LAMP3 & $0.3(0.5)$ & $0.3(0.4)$ & 0.516 \\
12 & CD83 & $0.005(0.021)$ & $0.000(0.034)$ & 0.127 \\
13 & & $0.1(0.1)$ & $0.1(0.2)$ & 0.139 \\
\hline 14 & & & &
\end{tabular}




\section{Table 3 (on next page)}

Univariate and multivariate analyses of variables associated with $\mathrm{ALN}^{+}$at diagnosis.

$\mathrm{ALN}^{+}=$metastatic axillary lymph node. $\mathrm{OR}=$ odds ratio. $\mathrm{Cl}=$ confidence interval.

$\mathrm{LVI}=$ lymphovascular invasion. $\mathrm{PNI}=$ perineural invasion. $\mathrm{ER}=$ oestrogen receptor.

$\mathrm{PR}=$ progesterone receptor. $\mathrm{HER}=$ human epidermal growth factor receptor. $\mathrm{Pl}=$ proliferation

index. Multivariate models 1 and 2 include variables from the univariate analyses with a level of significance of $p \leq 0.1$ and $p \leq 0.3$, respectively. 


\begin{tabular}{|c|c|c|c|c|c|c|}
\hline & $\begin{array}{l}\text { Univariate } \\
\text { OR }(95 \% \mathrm{Cl})\end{array}$ & $\mathbf{p}$ & $\begin{array}{c}\text { Multivariate } \\
\text { model } 1 \\
\text { OR }(95 \% \mathrm{Cl})\end{array}$ & $\mathbf{p}$ & $\begin{array}{c}\text { Multivariate } \\
\text { model } 2 \\
\text { OR }(95 \% \mathrm{Cl}) \\
\end{array}$ & $\mathbf{p}$ \\
\hline Age (years) & $0.99(0.96-1.02)$ & 0.392 & & & & \\
\hline Tumour diameter (mm) & $1.06(1.03-1.09)$ & 0.001 & & & & \\
\hline LVI & & & & & & \\
\hline $\begin{array}{l}\text { Present } \\
\text { Absent }\end{array}$ & $\begin{array}{l}24.2(10.0-58.5) \\
\quad . .\end{array}$ & $\begin{array}{c}<0.001 \\
. .\end{array}$ & $\begin{array}{c}25.3(9.54-66.90) \\
\quad . .\end{array}$ & $\begin{array}{c}<0.001 \\
. .\end{array}$ & $\begin{array}{c}372.28(13.22- \\
10485.09)\end{array}$ & $\begin{array}{c}0.001 \\
. .\end{array}$ \\
\hline $\begin{array}{l}\text { PNI } \\
\text { Present } \\
\text { Absent }\end{array}$ & $\begin{array}{l}4.36(1.94-9.83) \\
\quad . .\end{array}$ & $\begin{array}{c}<0.001 \\
. .\end{array}$ & & & & \\
\hline $\begin{array}{l}\text { Histological grade } \\
3 \\
2 \\
1\end{array}$ & $\begin{array}{l}6.55(2.45-17.5) \\
3.82(1.51-9.69) \\
\quad . .\end{array}$ & $\begin{array}{c}<0.001 \\
0.005 \\
. .\end{array}$ & $\begin{array}{l}5.13(1.40-18.94) \\
3.83(1.11-13.16)\end{array}$ & $\begin{array}{l}0.014 \\
0.033\end{array}$ & & \\
\hline $\begin{array}{l}\text { ER } \\
\text { Positive } \\
\text { Negative }\end{array}$ & $0.83(0.41-1.71)$ & $\begin{array}{c}0.617 \\
. .\end{array}$ & & & & \\
\hline $\begin{array}{l}\text { PR } \\
\text { Positive } \\
\text { Negative }\end{array}$ & $\begin{array}{l}0.58(0.30-1.13) \\
\quad . .\end{array}$ & $\begin{array}{c}0.108 \\
. .\end{array}$ & & & & \\
\hline $\begin{array}{l}\text { HER-2 } \\
\text { Amplified } \\
\text { Non-amplified }\end{array}$ & $\begin{array}{l}1.11(0.53-2.33) \\
\quad . .\end{array}$ & $\begin{array}{c}0.780 \\
. .\end{array}$ & & & & \\
\hline $\begin{array}{l}\text { PI (Ki 67) } \\
\text { High } \\
\text { Med } \\
\text { Low }\end{array}$ & $\begin{array}{l}2.36(1.04-5.40) \\
1.56(0.68-3.58) \\
\quad . .\end{array}$ & $\begin{array}{c}0.041 \\
0.292 \\
. .\end{array}$ & & & & \\
\hline $\begin{array}{l}\text { Menopausal status } \\
\text { Pre-menopausal } \\
\text { Post-menopausal }\end{array}$ & $0.46(0.18-1.18)$ & 0.106 & & & & \\
\hline $\begin{array}{l}\text { Molecular profile } \\
\text { HER-2 } \\
\text { TN } \\
\text { Luminal B } \\
\text { Luminal A }\end{array}$ & $\begin{array}{l}1.28(0.46-3.52) \\
1.15(0.41-3.24) \\
1.02(0.39-2.69) \\
\quad . .\end{array}$ & $\begin{array}{c}0.637 \\
0.792 \\
0.965 \\
. .\end{array}$ & & & & \\
\hline $\begin{array}{l}\text { Peritumoral immune } \\
\text { markers }\end{array}$ & & & & & & \\
\hline CD4 & $1.03(0.92-1.15)$ & 0.644 & & & & \\
\hline CD8 & $1.07(0.95-1.21)$ & 0.238 & & & & \\
\hline CD57 & $1.04(0.96-1.13)$ & 0.320 & & & & \\
\hline FOXP3 & $0.76(0.15-3.75)$ & 0.736 & & & & \\
\hline CD21 & $0.67(0.10-4.51)$ & 0.682 & & & & \\
\hline CD68 & $1.09(0.94-1.27)$ & 0.249 & & & $2.14(1.20-3.83)$ & 0.010 \\
\hline CD1a & $0.67(0.32-1.38)$ & 0.272 & & & & \\
\hline CD123 & $1.98(0.10-38.65)$ & 0.654 & & & & \\
\hline S100 & $0.64(0.28-1.44)$ & 0.282 & & & & \\
\hline LAMP3 & $5.73(0.25-129.3)$ & 0.272 & & & & \\
\hline CD83 & $3.54(0.54-23.28)$ & 0.188 & & & & \\
\hline
\end{tabular}




\section{Table 4 (on next page)}

Univariate and multivariate analyses (multiple imputation).

$\mathrm{ALN}^{+}=$metastatic axillary lymph node. $\mathrm{OR}=$ odds ratio. $\mathrm{Cl}=$ confidence interval.

$\mathrm{LVI}=$ lymphovascular invasion. $\mathrm{PNI}=$ perineural invasion. $\mathrm{ER}=$ oestrogen receptor.

$\mathrm{PR}=$ progesterone receptor. $\mathrm{HER}=$ human epidermal growth factor receptor. $\mathrm{Pl}=$ proliferation index. Multivariate models 1 and 2 include variables from the univariate analyses with a level of significance of $p \leq 0.1$ and $p \leq 0.3$, respectively. 


\begin{tabular}{|c|c|c|c|c|c|c|}
\hline & $\begin{array}{l}\text { Univariate } \\
\text { OR }(95 \% \mathrm{Cl})\end{array}$ & $\mathbf{p}$ & $\begin{array}{c}\text { Multivariate } \\
\text { model } 1 \\
\text { OR }(95 \% \mathrm{Cl})\end{array}$ & $\mathbf{p}$ & $\begin{array}{c}\text { Multivariate } \\
\text { model } 2 \\
\text { OR }(95 \% \mathrm{Cl})\end{array}$ & $\mathbf{p}$ \\
\hline Age (years) & $0.99(0.96-1.02)$ & 0.392 & & & & \\
\hline Tumour diameter (mm) & $1.06(1.03-1.09)$ & 0.001 & $1.04(1.00-1.07)$ & 0.057 & $1.04(1.00-1.08)$ & 0.038 \\
\hline \multicolumn{7}{|l|}{ LVI } \\
\hline Present & $24.2(10.0-58.5)$ & $<0.001$ & $25.27(9.54-$ & $<0.001$ & 27.58 (9.55- & $<0.001$ \\
\hline Absent & .. &.. & 66.90) & .. & 79.67) &.. \\
\hline \multicolumn{7}{|l|}{ PNI } \\
\hline $\begin{array}{l}\text { Present } \\
\text { Absent }\end{array}$ & $\begin{array}{l}4.36(1.94-9.83) \\
\quad . .\end{array}$ & $<0.001$ & & & & \\
\hline \multicolumn{7}{|l|}{ Histological grade } \\
\hline 3 & $6.55(2.45-17.5)$ & $<0.001$ & $5.13(1.39-18.94)$ & 0.014 & $6.43(1.49-27.75)$ & 0.013 \\
\hline 2 & $3.82(1.51-9.69)$ & 0.005 & $3.83(1.11-13.16)$ & 0.033 & $4.48(1.14-17.64)$ & 0.032 \\
\hline 1 & .. & & & & & \\
\hline \multicolumn{7}{|l|}{ ER } \\
\hline Positive & $0.83(0.41-1.71)$ & 0.617 & & & & \\
\hline Negative & .. & .. & & & & \\
\hline \multicolumn{7}{|l|}{ PR } \\
\hline $\begin{array}{l}\text { Positive } \\
\text { Negative }\end{array}$ & $\begin{array}{l}0.58(0.30-1.13) \\
\quad . .\end{array}$ & 0.108 & & & & \\
\hline \multicolumn{7}{|l|}{ HER-2 } \\
\hline $\begin{array}{l}\text { Amplified } \\
\text { Non-amplified }\end{array}$ & $\begin{array}{l}1.11(0.53-2.33) \\
\quad . .\end{array}$ & 0.780 & & & & \\
\hline \multicolumn{7}{|l|}{ PI (Ki 67) } \\
\hline High & $2.36(1.04-5.40)$ & 0.041 & & & & \\
\hline Medium & $1.56(0.68-3.58)$ & 0.292 & & & & \\
\hline Low & .. & .. & & & & \\
\hline \multicolumn{7}{|l|}{ Menopausal status } \\
\hline $\begin{array}{l}\text { Pre-menopausal } \\
\text { Post-menopausal }\end{array}$ & $\begin{array}{l}0.46(0.18-1.18) \\
\quad . .\end{array}$ & 0.106 & & & & \\
\hline \multicolumn{7}{|l|}{ Molecular profile } \\
\hline HER-2 & $1.28(0.46-3.52)$ & 0.637 & & & & \\
\hline $\mathrm{TN}$ & $1.15(0.41-3.24)$ & 0.792 & & & & \\
\hline Luminal B & $1.02(0.39-2.69)$ & 0.965 & & & & \\
\hline Luminal $\mathrm{A}$ & .. & & & & & \\
\hline \multicolumn{7}{|l|}{$\begin{array}{l}\text { Peritumoral immune } \\
\text { markers }\end{array}$} \\
\hline CD4 & $1.04(0.93-1.16)$ & 0.497 & & & & \\
\hline CD8 & $1.09(0.97-1.22)$ & 0.148 & & & & \\
\hline CD57 & 1.04 (0.97-1.12) & 0.250 & & & & \\
\hline FOXP3 & $1.00(0.998-1.001)$ & 0.555 & & & & \\
\hline CD21 & $0.80(0.13-5.00)$ & 0.815 & & & & \\
\hline CD68 & $1.12(0.97-1.29)$ & 0.132 & & & & \\
\hline CD1a & $0.76(0.50-1.14)$ & 0.757 & & & & \\
\hline CD123 & $1.71(0.24-12.25)$ & 0.594 & & & & \\
\hline S100 & $0.82(0.57-1.17)$ & 0.272 & & & & \\
\hline LAMP3 & $7.08(0.36-138.89)$ & 0.197 & & & & \\
\hline CD83 & $4.46(0.69-28.86)$ & 0.116 & & & & \\
\hline
\end{tabular}

